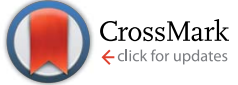

Cite this: RSC Adv., 2014, 4, 52241

Received 18th August 2014

Accepted 13th October 2014

DOI: 10.1039/c4ra08861a

www.rsc.org/advances

\title{
Diazo group as a new chemical reporter for bioorthogonal labelling of biomolecules $\uparrow$
}

\author{
Laia Josa-Culleré, ${ }^{a}$ Yelena A. Wainman, ${ }^{a}$ Kevin M. Brindle ${ }^{b}$ and Finian J. Leeper ${ }^{\star a}$ \\ Diazoacetyl groups have been shown to undergo spontaneous cycloaddition reactions with strained \\ alkenes and alkynes. The rates of reaction are similar to the equivalent reactions of azide groups. This \\ allows diazo groups to be used as bioorthogonal reporter groups. This is demonstrated by fluorescent \\ labelling of a diazoacetylated protein and of cell-surface glycans via metabolic incorporation of a \\ diazoacetylated sugar.
}

\section{Introduction}

For in vivo molecular imaging, small molecules have better access to extravascular compartments and show better clearance of unbound material than macromolecules such as antibodies and lectins. Their use as imaging agents requires them to target selectively the desired biomolecule. One way to achieve this is to use the bioorthogonal chemical reporter strategy, in which the target of interest is labelled in a two-step process. Firstly, a bioorthogonal chemical reporter is incorporated into the target of interest using the cell's own biosynthetic machinery. This can be achieved by attaching a suitable reporter to substrates that can be metabolised by the cell. For example, some unnatural amino acids can be incorporated into proteins or monosaccharides bearing bioorthogonal functional groups can be introduced into cell-surface glycans by enzymes that tolerate the unnatural motif. Secondly, the chemical reporter is then reacted with a small molecule probe that has a complementary bioorthogonal reactive moiety. The bioorthogonal reaction partners should react rapidly under physiological conditions $\left(37^{\circ} \mathrm{C}, \mathrm{pH}\right.$ 6-8) and remain inert to other biological functional groups, they should form a stable and non-toxic product and have no or inert by-products. The bioorthogonal reporter strategy has proved to be a powerful tool to image glycans, ${ }^{1-4}$ proteins $^{5-7}$ and lipids. ${ }^{8}$

The number of functional groups that have been shown to possess all the requisites to be useful chemical reporters is limited. This group comprises peptide motifs that can be tagged with small-molecule imaging probes, ${ }^{5,9}$ ketones and aldehydes that can be ligated with hydrazine and hydroxylamine derivatives, ${ }^{\mathbf{1 , 6}, \mathbf{1 0}}$ azides that can be modified with phosphines or

${ }^{a}$ University of Cambridge, Department of Chemistry, Lensfield Road, Cambridge, CB2 1EW, UK.E-mail: fjl1@cam.ac.uk

${ }^{b}$ Cancer Research UK, Cambridge Institute, Li Ka Shing Centre, Robinson Way, Cambridge CB2 ORE, UK

$\dagger$ Electronic supplementary information (ESI) available: Experimental data and NMR spectra. See DOI: 10.1039/c4ra08861a reactive alkynes, ${ }^{7,8,11-13}$ terminal alkynes that can be tagged with azides, ${ }^{14}$ and strained alkenes ${ }^{15-20}$ and isonitriles ${ }^{21}$ that can be ligated with tetrazines. Amongst these, azides have been the most widely used because of their chemical stability and small size.

The reaction of diazo compounds with alkenes and alkynes has been known for many years ${ }^{22}$ yet little attention has been paid to its potential as a new chemical reporter group. In this paper, we present a proof-of-principle study where we first evaluated the rate of cycloaddition reactions of a diazo compound with a strained alkene and an alkyne. We also demonstrated the bioorthogonality of the diazo group by labelling a protein and tested the incorporation of diazobearing sugars into cell-surface glycans.

\section{Results and discussion}

\section{Kinetic studies with the diazo group}

The highly strained (E,E)-1,5-cyclooctadiene (COD) 2 has been reported to perform very efficient $[3+2]$ cycloadditions with 1,3 dipoles and inverse-electron-demand Diels-Alder reactions with tetrazines, making it suitable for applications in chemical ligation. ${ }^{23}$ In order to test whether the diazo group could be used as a chemical reporter in a two-step labelling process, its reaction with $(E, E)$-COD followed by reaction of the adduct formed with tetrazine was explored. $(E, E)$-COD was prepared from $(Z, Z)$-COD via a three-step phosphine oxide-mediated olefin inversion. ${ }^{24}$ It was found to react cleanly with ethyl diazoacetate 1 by a [3+2] cycloaddition to give pyrazoline 3 after tautomerisation (Fig. 1). The second-order rate constant of this reaction was measured by UV spectroscopy (Fig. S3a $\dagger$ ) in pentane at room temperature to be $0.045 \pm 0.002 \mathrm{M}^{-1} \mathrm{~s}^{-1}$. The rate constant of the second [3+2] cycloaddition, giving $4 \mathbf{4}$ and 4b, was measured by ${ }^{1} \mathrm{H}$ NMR spectroscopy in $\mathrm{CD}_{3} \mathrm{OD}$ at room temperature and is two orders of magnitude lower, which can be explained by the relief of ring strain once the first trans double bond of 2 has reacted. Thus pyrazoline 3 can be obtained 


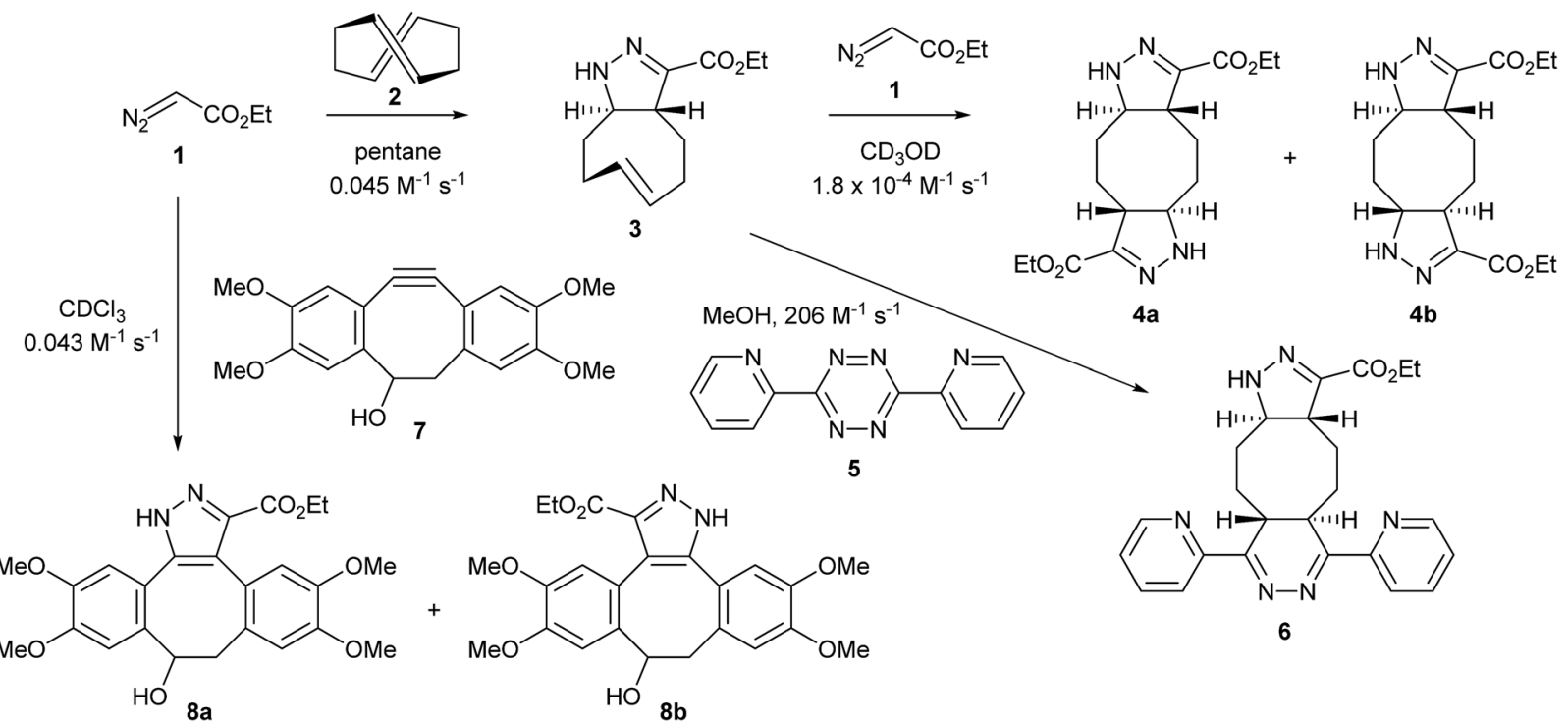

Fig. 1 Cycloaddition of ethyl diazoacetate with $(E, E)$-COD 2 and TMDIBO 7 and inverse-electron-demand Diels-Alder with tetrazine 5, with measured rate constants.

in almost quantitative yield by reaction of equimolar amounts of $\mathbf{1}$ and 2. The inverse-electron-demand Diels-Alder reaction of the remaining trans double bond of $\mathbf{3}$ with tetrazine $\mathbf{5}$ to give the dihydropyridazine adduct 6 was then measured by UV spectroscopy in $\mathrm{MeOH}$ at room temperature and proceeded, as expected, at a much faster rate, $206 \pm 6 \mathrm{M}^{-1} \mathrm{~s}^{-1}$.

Therefore, using 2 as an intermediary, two consecutive click reactions can ligate a diazo ester to a tetrazine, which could potentially bear an imaging agent. The rates of these two click reactions are of the same order of magnitude as for an azide group reacting with first $\mathbf{2}$ and then $\mathbf{5}$, the first one being 2 -fold faster and the second one 2 -fold slower. However, because of the lack of solubility in water and volatility of 2 , it cannot be used as a reagent with a diazo chemical reporter in biological systems. Therefore, we used instead an alternative $[3+2]$ cycloaddition with TMDIBO 7, a stable dibenzocyclo-octyne developed previously by our group and used for imaging of cell-surface azido sugars. ${ }^{25}$ Its reaction with ethyl diazoacetate 1 to give $\mathbf{8 a}$ and $\mathbf{8 b}$ was followed by ${ }^{1} \mathrm{H}$ NMR spectroscopy in $\mathrm{CDCl}_{3}$ at room temperature and proved to have almost exactly the same rate as for the cycloaddition of $\mathbf{1}$ with $(E, E)$-COD 2, with a second-order rate constant of $0.043 \pm 0.004 \mathrm{M}^{-1} \mathrm{~s}^{-1}$. This cycloaddition of diazo compounds with strained alkynes has only recently been reported by McGrath and Raines. ${ }^{26}$

\section{Bioorthogonal labelling of diazo-modified sugars and proteins}

The bioorthogonality of the diazo group was tested by incubating ethyl diazoacetate with $10 \mathrm{mM}$ glutathione at $\mathrm{pH} 7.4$ and $37{ }^{\circ} \mathrm{C} .{ }^{1} \mathrm{H}$ NMR spectroscopy showed no significant reaction after $24 \mathrm{~h}$ (see ESI, Fig. S5 $\dagger$ ), indicating that diazoesters do not react with biologically relevant functional groups (thiols, carboxylic acids and amines).

In order to demonstrate the use of the diazo group as a bioorthogonal labelling agent, its ability to label proteins was tested. A solution of lysozyme was incubated with the diazoacetate NHS ester 9 (ref. 27) for $3 \mathrm{~h}$ to prepare the diazomodified protein (Fig. 2). The protein was then purified by gel
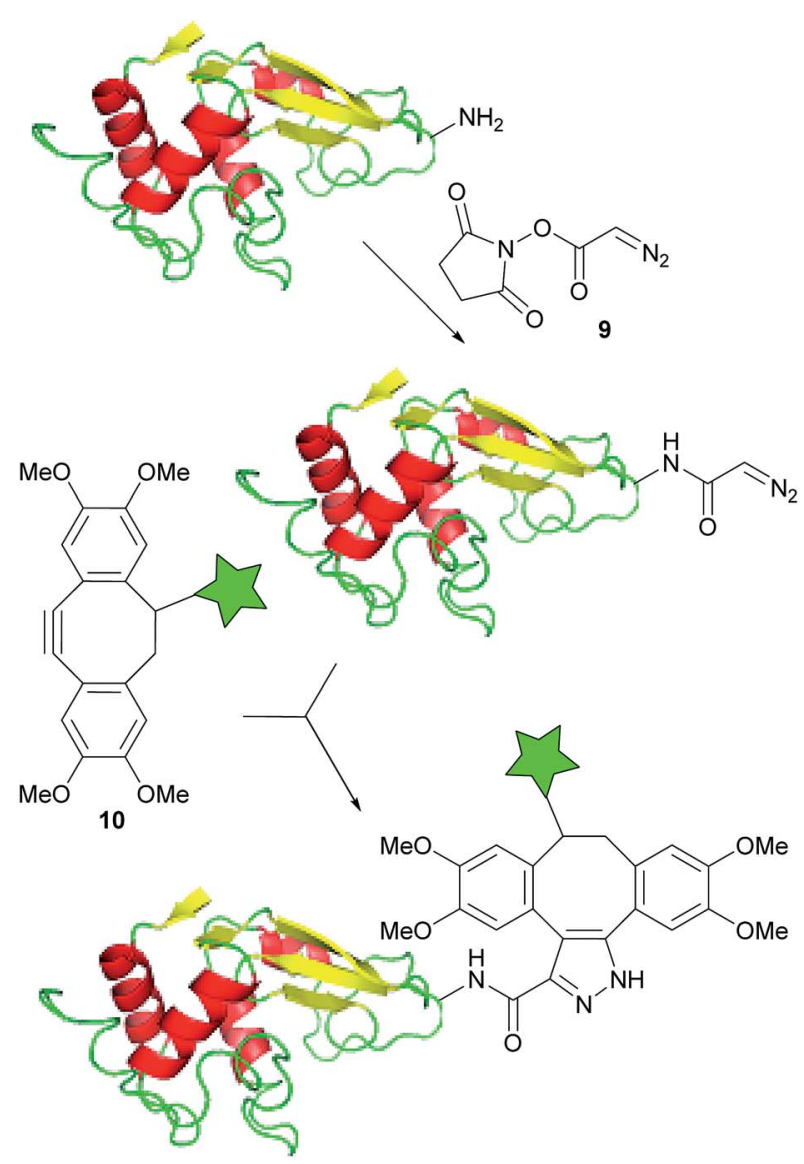

Fig. 2 Fluorescence-labelling of diazo-modified lysozyme. The star represents the fluorophore (fluorescein). 
filtration, labelled with different concentrations of a TMDIBOfluorescein complex $\mathbf{1 0}$ and then run on a SDS-polyacrylamide gel. Fluorescence imaging of the gel showed concentrationdependent labelling of the protein, co-localised with the protein bands as shown by Coomassie Blue staining (see Fig. S7†).

We next studied the application of the diazo group for the metabolic labelling of cell-surface glycans. Tetra-O-acetylgalactosamine hydrochloride $\left(\mathrm{Ac}_{4} \mathrm{GalNH}_{3} \mathrm{Cl}\right.$ 12) was prepared in anomerically pure form from galactosamine $\mathbf{1 1}$ by the three-

\section{A}

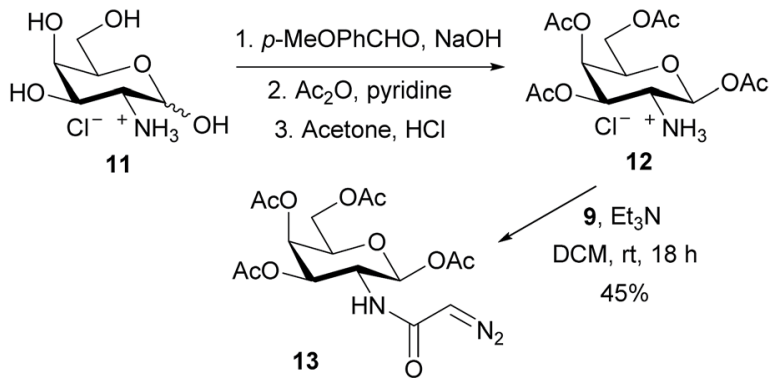

B

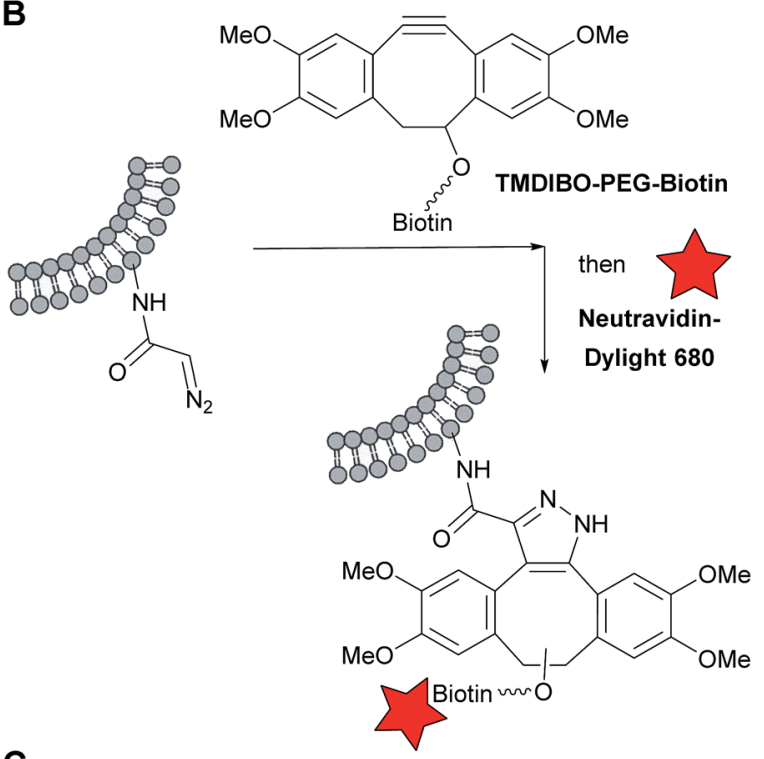

C

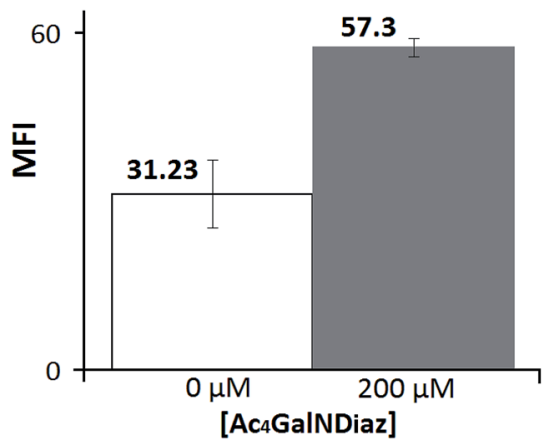

Fig. 3 (A) Synthesis of tetra-O-acetyl- $N$-diazoacetylgalactosamine 13; (B) detection of diazo-modified glycans on LL2 cancer cells surface; (C) flow cytometry results. M.F.I. = mean fluorescence intensity in the far-red channel. Error bars represent standard deviation for three repeats. step process of Faroux-Corlay et al. ${ }^{28}$ involving protection of the amine as its imine with anisaldehyde. The diazoacetyl derivative $\left(\mathrm{Ac}_{4} \mathrm{GalNDiaz}, 13\right)$ was then synthesised using NHS ester 9 (Fig. 3A). In metabolic labelling of glycans, the sugar precursor is normally administered in $O$-peracetylated form as this increases cellular uptake; the sugars are deacylated inside the cell by endogenous esterases. ${ }^{29}$

Lewis lung carcinoma (LL2) cells were incubated with a medium containing 0 or $200 \mu \mathrm{M}$ of the diazo sugar for $24 \mathrm{~h}$. To detect diazo groups incorporated into the cell-surface glycans, the cells were washed, treated with TMDIBO-PEG-biotin (Fig. 3B) for $30 \mathrm{~min}$, washed again, treated with NeutravidinDylight680 for $15 \mathrm{~min}$, washed again, and analysed by flow cytometry. This two-step labelling procedure, labelling first with biotin and then visualising this with fluorescently labelled Neutravidin gives an improved signal-to-background ratio compared to a one-step procedure using, for example, a TMDIBO-fluorophore conjugate such as $1 \mathbf{1 0}^{30}$ Furthermore, Neutravidin, being a large protein, is completely impermeable to the cells. Therefore any increase in fluorescence must be due to diazo groups on the cell-surface and not intracellular diazo groups.

The flow cytometry results showed a clear increase in fluorescence in cells incubated with the diazosugar compared to untreated cells, As shown in Fig. 3C, the mean fluorescence almost doubled (see ESI $\dagger$ for a representative histogram). This shows that some diazo groups have survived and been incorporated into cell-surface glycans. However the level of labelling is much lower than one would typically expect with the equivalent azido sugar. ${ }^{25}$ The reason(s) for this are not known at present. $N$-Diazoacetylgalactosamine may be a poor substrate for one or more enzymes of the galactosamine salvage pathway or of glycan biosynthesis, even though the diazoacetyl group is smaller than the azidoacetyl group. However it is a different shape, preferring a planar conformation, and this may be detrimental to binding to some enzymes. Alternatively it may be that the $\mathrm{N}$-diazoacetylgalactosamine is diverted into a different pathway, involving either enzymic degradation or incorporation into some intracellular entity. It may well be that other diazolabelled sugars would be better incorporated - the enzymes required for incorporation of $N$-acetylmannosamine into sialic acid residues of cell-surface glycans are known to be particularly tolerant of additional bioorthogonal reporter groups. ${ }^{31}$

\section{Conclusions}

We have been able to show that the diazo group can be used as a new chemical reporter for bioorthogonal imaging. The reaction rates with the strained trans-cyclooctene 2 and dibenzocyclooctyne 7 are of the same order of magnitude as for azides, which is a widely used chemical reporter. The labelling of lysozyme shows that diazoacetyl groups are compatible with all the functional groups present in proteins, while the labelling of cell-surface glycans shows that metabolic incorporation of diazo groups is also a possibility. The small size of the diazo group (smaller even than azide) may well make it the chemical reporter group of choice in certain instances. 


\section{Acknowledgements}

We thank Will Crone and Terence Kwan for technical assistance and Henning Stöckmann for the TMDIBO-PEG-biotin. L.J.C. was in receipt of the scholarship La Caixa and Y.A.W. was recipient of Cancer Research UK funding.

\section{Notes and references}

1 L. K. Mahal, K. J. Yarema and C. R. Bertozzi, Science, 1997, 276, 1125-1128.

2 E. Saxon, S. J. Luchansky, H. C. Hang, C. Yu, S. C. Lee and C. R. Bertozzi, J. Am. Chem. Soc., 2002, 124, 14893-14902.

3 S. J. Luchansky, H. C. Hang, E. Saxon, J. R. Grunwell, C. Y. Danielle, D. H. Dube and C. R. Bertozzi, Methods Enzymol., 2003, 362, 249-272.

4 S. J. Luchansky, S. Goon and C. R. Bertozzi, ChemBioChem, 2004, 5, 371-374.

5 B. A. Griffin, S. R. Adams and R. Y. Tsien, Science, 1998, 281, 269-272.

6 Z. W. Zhang, B. A. C. Smith, L. Wang, A. Brock, C. Cho and P. G. Schultz, Biochemistry, 2003, 42, 6735-6746.

7 A. J. Link, M. K. S. Vink and D. A. Tirrell, J. Am. Chem. Soc., 2004, 126, 10598-10602.

8 Y. Kho, S. C. Kim, C. Jiang, D. Barma, S. W. Kwon, J. K. Cheng, J. Jaunbergs, C. Weinbaum, F. Tamanoi, J. Falck and Y. M. Zhao, Proc. Natl. Acad. Sci. U. S. A., 2004, 101, 12479-12484.

9 S. R. Adams, R. E. Campbell, L. A. Gross, B. R. Martin, G. K. Walkup, Y. Yao, J. Llopis and R. Y. Tsien, J. Am. Chem. Soc., 2002, 124, 6063-6076.

10 I. Chen, M. Howarth, W. Y. Lin and A. Y. Ting, Nat. Methods, 2005, 2, 99-104.

11 A. E. Speers, G. C. Adam and B. F. Cravatt, J. Am. Chem. Soc., 2003, 125, 4686-4687.

12 J. A. Prescher, D. H. Dube and C. R. Bertozzi, Nature, 2004, 430, 873-877.

13 N. J. Agard, J. A. Prescher and C. R. Bertozzi, J. Am. Chem. Soc., 2005, 127, 11196.

14 A. E. Speers and B. F. Cravatt, Chem. Biol., 2004, 11, 535-546.
15 R. Rossin, P. R. Verkerk, S. M. van den Bosch, R. C. M. Vulders, I. Verel, J. Lub and M. S. Robillard, Angew. Chem., Int. Ed., 2010, 49, 3375-3378.

16 N. K. Devaraj, R. Weissleder and S. A. Hilderbrand, Bioconjugate Chem., 2008, 19, 2297-2299.

17 D. M. Patterson, L. A. Nazarova, B. Xie, D. N. Kamber and J. A. Prescher, J. Am. Chem. Soc., 2012, 134, 18638-18643.

18 C. M. Cole, J. Yang, J. Seckute and N. K. Devaraj, ChemBioChem, 2013, 14, 205-208.

19 J. Yang, J. Seckute, C. M. Cole and N. K. Devaraj, Angew. Chem., Int. Ed., 2012, 51, 7476-7479.

20 J. Schoch, M. Wiessler and A. Jaschke, J. Am. Chem. Soc., 2010, 132, 8846-8847.

21 S. Stairs, A. A. Neves, H. Stockmann, Y. A. Wainman, H. Ireland-Zecchini, K. M. Brindle and F. J. Leeper, ChemBioChem, 2013, 14, 1063-1067.

22 R. Huisgen, in 1,3-Dipolar Cycloaddition Chemistry, ed. A. Padwa, Wiley, New York, 1984.

23 H. Stockmann, A. A. Neves, H. A. Day, S. Stairs, K. M. Brindle and F. J. Leeper, Chem. Commun., 2011, 47, 7203-7205.

24 D. Boeckh, R. Huisgen and H. Noth, J. Am. Chem. Soc., 1987, 109, 1248-1249.

25 H. Stockmann, A. A. Neves, S. Stairs, H. Ireland-Zecchini, K. M. Brindle and F. J. Leeper, Chem. Sci., 2011, 2, 932-936.

26 N. A. McGrath and R. T. Raines, Chem. Sci., 2012, 3, 32373240 .

27 A. Ouihia, L. Rene, J. Guilhem, C. Pascard and B. Badet, J. Org. Chem., 1993, 58, 1641-1642.

28 B. Faroux-Corlay, L. Clary, C. Gadras, D. Hammache, J. Greiner, C. Santaella, A. M. Aubertin, P. Vierling and J. Fantini, Carbohydr. Res., 2000, 327, 223-260.

29 C. L. Jacobs, K. J. Yarema, L. K. Mahal, D. A. Nauman, N. W. Charters and C. R. Bertozzi, Methods Enzymol., 2000, 327, 260-275.

30 A. A. Neves, H. Stockmann, Y. A. Wainman, J. C. H. Kuo, S. Fawcett, F. J. Leeper and K. M. Brindle, Bioconjugate Chem., 2013, 24, 934-941.

31 J. Du, M. A. Meledeo, Z. Wang, H. S. Khanna, V. D. P. Paruchuri and K. J. Yarema, Glycobiology, 2009, 19, 1382-1401. 